\title{
Heart failure - or a failure of imagination?
}

\section{John Launer}

Over ten years ago, Richard Lehman wrote an editorial in the $B M J$ proposing that we should abandon the term heart failure. ${ }^{1}$ Instead, he suggested, 'it might be kinder, and more accurate, to start calling it cardiac impairment.' As Lehman argued, the term heart failure covers a confusingly wide spectrum of illness ranging from asymptomatic systolic dysfunction to imminent death from pulmonary oedema, while for patients it has 'a deadly ring of finality.' His entirely reasonable suggestion never caught on, although many physicians who deal with heart disease continue to point out how deeply problematical the notion is, both in terms of clinical precision and patient impact. For example, in a book entitled 'Living Well with Heart Failure - The Misnamed, Misunderstood Condition', US cardiologist Edward K Kasper and his co-author Mary Knudson summarise the inadequacy of the term in one brief line: 'Heart failure? No. Language failure, that's all.,'

It would be of sufficient concern if confusion around cardiac impairment was simply due to language (and in the rest of this article, I shall use Lehman's alternative term, hoping that this might encourage others to do so as well) Unfortunately, the word 'failure' also underpins an impoverished view of what cardiac impairment actually means in terms of function, progression and life expectancy. With little difficulty, you can find statistics on the internet stating that 5 year survival from the date of initial diagnosis is somewhere between 25 and 50 per cent - even when stated by reputable cardiology associations and heart disease charities,. These figures are sometimes noted to be similar to those in incurable cancers. What these sources often fail to make clear is that such statistics are largely historical. They generally represent populations that may have been relatively older, diagnosed later, or undertreated by modern standards. ${ }^{3}$ By contrast, one large scale survey in Minnesota showed a 5 year survival of 96 per cent in patients with asymptomatic

Correspondence to Dr John Launer, Health Education England, Stewart House, 32 Russell Square, London WC1H 5DN, UK; johnlauner@aol.com left ventricular dysfunction, and 75 per cent in those with non-severe dyspnoea or fatigue. ${ }^{4}$ Many people were unaware they had cardiac impairment of any kind until they had echocardiograms as part of the survey. Only in a very small number of patients who had severe symptoms was survival as low as commonly stated - or as many doctors and patients continue to believe.

\section{INFORMED CONVERSATIONS}

The combination of misleading terminology with disinformation probably leads to the kind of conversations with physicians that patients sometimes report. One person I know was bluntly told last year that he had 'severe heart failure' on the basis of his echocardiogram result alone. He was put on small doses of a beta-blocker, ACE inhibitor, aldosterone antagonist and statin, and sent back to see his general practitioner for 'routine care' without any further guidance. After a period of near despair, he was referred to another cardiologist, who reassured him that the 'severity' of his condition related only to his systolic ejection fraction, and had relatively little bearing on his prognosis in the absence of any notable symptoms, let alone assessing the effect of any treatment. Together, the cardiologist and patient looked at the Seattle Heart Failure Model - an online resource that allows calculation of mean life expectancy. ${ }^{5}$ By entering his parameters, they established that he could expect an average of around another decade of life even without any treatment, and twice that length with optimal doses of medication. While the words and manner of the first cardiologist had led the patient to assume he had virtually no future, the conversation with the second one gave him a far more positive attitude, and provided the motivation he needed to take his medication seriously.

Informed conversations like this can make a huge difference, but they need to happen regularly in order to achieve better outcomes for all. The leading cardiac researcher Milton Packer has highlighted that the treatment of cardiac impairment 'requires a great deal of work on the part of both the patient and the physician.' According to Packer, patients 'need to be told that they can really make an impact on their disease, and they need to find a physician who is willing to make the commitment to do so. ${ }^{6}$ Treatment involves far more than just pills and sometimes pacemakers. It needs frequent monitoring of signs, symptoms and investigative results, careful calibration of dosages against side effects, and a relationship of frankness and trust that may last for many years.

This raises the question of why it is still so common for patients to receive care that is crisis-driven rather than proactive and following well-established international guidelines. ${ }^{7}$ There is a notable contrast here to the way that patients with other chronic conditions like diabetes and chronic obstructive pulmonary disease are often managed. In the United Kingdom, for example, many primary care clinics have dedicated services for such conditions, often run by specially trained nurses and with close liaison with local hospital specialists. There seems no reason why the equivalent services should not be just as routine for cardiac impairment.

\section{Planned palliative care}

Finally, there is another kind of resource for cardiac impairment that also seems to remain a Cinderella service. When they approach the end of life, patients are likely to have an accelerated number of acute hospital admissions, rather than receiving well-planned and organised palliative care. ${ }^{8}$ In this respect, a comparison with incurable cancer really is valid. A report this May from the organisation Hospice UK has pointed out that each year around the same proportion of deaths arise from heart disease as from cancer. In spite of this, only four per cent of people cared for by hospices and palliative care teams are cardiac patients, compared with 70 per cent who have cancer. ${ }^{9}$ The authors of the report make a strong case for involving hospices in service design and delivery for cardiac impairment. This includes making palliative care and assessment service far more widely available. They argue that patients who have indicators of end stage disease, including breathlessness at rest or on slight exertion, might be far more better looked after in hospices than on acute medical wards, and that hospice admission could be used periodically for symptom management, not only in the patient's final days.

To paraphrase Kasper and Knudson, the problem may not be heart failure, so much as a failure of imagination. There is a need for an altered mindset right across 


\section{On reflection}

the board where cardiac impairment is concerned, involving changes in language, expectations, conversations with patients, professional commitment, organisation of services and attitudes to the end of life. The knowledge, treatments and service models for these changes are all available. It is surely time to apply them.

Competing interests None declared.

Provenance and peer review Commissioned; internally peer reviewed.

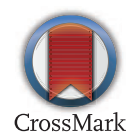

To cite Launer J. Postgrad Med J 2017;93:439-440. Postgrad Med J 2017:93:439-440. doi:10.1136/postgradmedj-2017-135118
(C) Article author(s) (or their employer(s) unless otherwise stated in the text of the article) 2017. All rights reserved. No commercial use is permitted unless otherwise expressly granted.

\section{REFERENCES}

1 Lehman R, Doust J, Glasziou P. Cardiac impairment or heart failure? BMJ 2005;331:415-6.

2 Kaspar EK, Knudson M. Heart Failure - The Misnamed, Misunderstood Condition. Baltimore: Johns Hopkins University Press, 2010.

3 Knudson M. Heart failure death statistics: Don't believe what you read on the internet. CardioBrief, 1 Dec 2010. http://www.cardiobrief.org/2010/12/ 01/heart-failure-death-statistics-don\%E2\%80\%99tbelieve-what-you-read-on-the-internet/ (accessed 31 May 2017).

4 Ammar KA, Jacobsen SJ, Mahoney DW, et al. Prevalence and prognostic significance of heart failure stages: application of the American College of Cardiology/
American Heart Association heart failure staging criteria in the community. Circulation 2007;115:1563-70.

5 Seattle Heart failure Model. University of Washington. https://depts.washington.edu/shfm/index.php (accessed 31 May 2017).

6 Husten L. A conversation about heart failure with Milton Packer and Richard Lehman. CardioBrief, 17 May 2017; http://www.cardiobrief.org/2017/05/17/ a-conversation-about-heart-failure-with-milton-packerand-richard-lehman (accessed 31 May 2017).

7 Ponitowski P, Voors AA, Anker SD. ESC Guidelines for the diagnosis andtreatment of acute and chronic heart failure. Eur Heart J 2016;37:2129-200.

8 Johnson M, Lehman R, Hogg KJ. Heart Failure and Palliative Care: A Team Approach. 2nd edition. London: CRC Press, 2015

9 Hospice UK. Heart failure and hospice care: How to make a difference. London: Hospice UK, 2017. https:// www.hospiceuk.org/docs/default-source/What-WeOffer/Care-Support-Programmes/heart-failure-andhospice-care_web.pdf?sfvrsn=2. (accessed 31 May 2017). 